\title{
Uma hermenêutica africana: Tertuliano e a teologia
}

\section{An African hermeneutics: Tertullian and theology \\ Una hermenéutica africana: Tertuliano y teología}

\author{
Graham Gerald McGeoch*
}

\begin{abstract}
RESUMO
Este artigo propõe revisitar a teologia de Tertuliano por meio da discussão de várias correntes da teologia contemporânea. Há poucos textos de Tertuliano disponível em língua portuguesa, apesar de sua influência douradora na teologia. Frequentemente, textos de Tertuliano são lidos e interpretados à luz de outras disciplinas além da teologia. Pretende-se recuperar o valor de Tertuliano e sua teologia em discussões teológicas atuais, levando em consideração a "virada patrística" na "ortodoxia radical" (teologia ocidental) e a "síntese neopatrística" (teologia oriental). O foco do artigo é a relação de Tertuliano com a teologia africana.

Palavras-chaves: Tertuliano; hermenêutica africana; Teologia da Libertação; ortodoxia radical; síntese neopatrística.
\end{abstract}

\begin{abstract}
This article proposes to revisit Tertullian's theology through discussion of various contemporary theologies. There are few of Tertullian's texts available in the Portuguese language, despite his lasting influence on theology. Often, Tertullian's texts are read and interpreted in light of other disciplinary areas outside of theology. It is hoped to recover the value of Tertullian and his theology in current theology discussions, taking into consideration the "patristic turn" in "Radical Orthodoxy" (Western Theology) and the "Neo-Patristic Synthesis" (Eastern Theology). The focus of the article is Tertullian's relation to African Theology.

Keywords: Tertullian; african hermeneutics; Liberation Theology; Radical Orthodoxy; Neo-Patristic synthesis.

RESUMEN

Este artículo propone volver a visitar la teología de Tertuliano a través de la discusión de varias corrientes de la teología contemporánea. Hay pocos textos de Tertuliano disponibles en portugués, a pesar de su influencia dorada en la teología. Los textos tertulianos a menudo se leen e interpretan a la luz de disciplinas distintas de la teología. Su objetivo es recuperar el valor de Tertuliano y su teología en las discusiones teológicas actuales, teniendo en cuenta el "giro patrístico" en la "ortodoxia radical" (teología occidental) y la "síntesis neopatrista" (teología oriental). El enfoque del artículo es la relación de Tertuliano con la teología africana. Palabras clave: Tertuliano; hermenéutica africana; Teología de la Liberación; ortodoxia radical; síntesis neo-patrística.
\end{abstract}

* Prof. Dr. da Faculdade Unida de Vitória (Espírito Santo, Brasil). E-mail: graham@faculdadeunida. com.br 


\section{Introdução}

Como ensinar Tertuliano na academia, e especificamente num curso de teologia? A primeira dificuldade que enfrentamos é a escassez de fontes que disponibilizam os textos de Tertuliano em português. ${ }^{1}$ A segunda dificuldade é a escolha de abordagem em termos de campos disciplinares. As abordagens possíveis são várias. Em termos de campos disciplinares, na academia brasileira a preferência é obviamente filosofia e letras nas universidades públicas. Assim, os escritos de Tertuliano passam a ser lidos, interpretados e discutidos em análises filosóficas ou linguísticas.

Um excelente exemplo deste tipo de abordagem é a tradução e comentário do opúsculo Adversus Valentinanos realizado Ivan Baycer Junior (2016). Ele oferece a primeira tradução para língua portuguesa deste texto de Tertuliano. Por meio de uma análise partindo dos preceitos da retórica clássica, ele demonstrou a importância do texto de Tertuliano para a construção da "proto-ortodoxia". Por sua vez, ele emprestou o termo "proto-ortodoxia" não da retórica clássica, mas de outros campos disciplinares inclusive da teologia. Especificamente, ele citou o trabalho de Jean Daniel Dubois e Jean Daniélou.

Esta perspectiva sobre Tertuliano e a "proto-ortodoxia" apresentada por Ivan Baycer Junior não é nenhuma novidade para o campo disciplinar da teologia. Enquanto parece óbvio que a preferência disciplinar seja a filosofia ou letras nas universidades públicas, Tertuliano era teólogo. Assim, há uma certa possibilidade de estudos interdisciplinares entre filosofia, letras e teologia.

Porém, como a pergunta inicial é como ensinar Tertuliano num curso de teologia, o foco da discussão passa para o campo da teologia. Longe de resolver a questão da abordagem disciplinar em relação ao Tertuliano, optar para uma abordagem teológica é apenas o começo dos problemas. Importante salientar que a teologia não se restringe apenas ao estudo das ortodoxias (ou proto-ortodoxias) e heresias. George Lindbeck já demonstrou as limitações de abordagens teológicas que interpretam doutrinas apenas como "proposições informativas" ou "reivindicações de verdades sobre realidades objetivas” (1984, p. 80).

(Apesar desta limitação, Rubem Alves já observou que o protestantismo brasileiro se baseia em "proposições informativas" repetidas (ALVES, 2005, p. 156). O catecismo (a educação cristã) é visto como bem sucedido quando o(a) novo(a) convertido(a) consegue repetir de cor as "proposições informativas". $\mathrm{Na}$ perspectiva de Alves, este tipo de teologia não nasce da experiência, e nem

\footnotetext{
1 Apesar da sua importância para teologia, é notável a escassez de material de Tertuliano comparado com Agostinho por exemplo.
} 
esclarece a relação entre Atenas e Jerusalém nas "proposições informativas". O anti-intelectualismo no protestantismo brasileiro não faz a pergunta, "qual é sua opinião [teológica] a cerca de...” (ALVES, 2005, p. 158)).

Lindbeck, entre outros, é uma influência na virada hermenêutica da teologia. Especificamente, ele propõe uma abordagem cultural-linguística para a teologia, "tecnicamente, a religião pode ser vista como um tipo de paradigma ou meio cultural e/ou linguístico que dá forma à vida e pensamento inteiro" (LINDBECK, 1984, p. 33). Porém, como notou Werner Jeanrond, uma virada hermenêutica necessita um esclarecimento sobre a relação entre teologia e hermenêutica. Jeanrond identifica três posições básicas: (a) teologia como subdisciplina da hermenêutica; (b) teologia com sua própria hermenêutica; (c) teologia independente da hermenêutica (JEANROND, 1994, p. 163). Apesar disso ser um debate da teologia ocidental do século XX e XXI, Tertuliano pode contribuir para este esclarecimento. Especificamente, reconsiderando Tertuliano como teólogo africano com uma hermenêutica africana.

\section{Tertuliano e a teologia}

Talvez Tertuliano pareça uma opção estranha para iniciar um diálogo sobre uma hermenêutica africana. As objeções podem ser muitas: ele é possivelmente o primeiro teólogo a escrever em Latim, e, portanto, se torna uma pedra fundamental da tradição latina, ocidental, católico-romana e protestante. Ele é percursor de muitas ortodoxias cristãs declaradas sensus fidelium pelos concílios ecumênicos, entre quais a Trindade, "uma substância em três pessoas" e a Cristologia, "uma natureza e duas pessoas", para não mencionar o conceito (latino e ocidental tanto na sua vertente católico-romana quanto protestante) de "pecado original herdado". No entanto, ele inicia uma discussão sem fim dentro do cristianismo sobre a relação entre filosofia (Atenas) e teologia (Jerusalém) com sua pergunta celebre, "O que Atenas tem a ver com Jerusalém?” (STEVENSON, 2002, p. 167).

Como demonstrou Nicholas Walterstorff, esta pergunta de Tertuliano é douradora para cristãos, e para a teologia ocidental. Frequentemente, ela é apresentada em termos de oposição entre filosofia estoica e as Sagradas Escrituras (WALTERSTORFF, 1999, p. 7). Também, o texto De Praescritione Haereticorum [Contra Heresias] é lido e interpretado como uma justaposição entre a filosofia e a teologia. Neste tipo de leitura, toda filosofia (grega) é vista como suspeita pela teologia e interpretada como fonte de possível corrupção das verdades divinas reveladas. Tal suspeita vai se expressando e se consolidando através dos séculos pela divisão entre teologia e ciência. E na 
sua expressão mais fundamentalista - conforme definida por George Marsden (1991) - ela vai se expressar como anti-intelectualismo em certas correntes de massa do cristianismo contemporâneo. Wolterstorff corretamente avaliou que a pergunta e seus efeitos são douradoros para o cristianismo.

Há duas linhas principais na teologia contemporânea que parte deste tipo de leitura de Tertuliano. Na teologia ocidental, John Milbank e a escola de "ortodoxia radical" trabalham de forma frutífera a ideia dos limites da razão secular (enraizada na filosofia iluminista, que por sua vez é herdeira da filosofia grega). Milbank questiona profundamente a relação que a teologia mantém com as ciências sociais em termos de paradigmas que explicam a religião e a realidade. $\mathrm{Na}$ linha da tradição ocidental de interpretação de Tertuliano, Milbank propõe uma reavaliação da relação entre teologia e ciências sociais (inclusive filosofia). A proposta dele é que a teologia deveria se reafirmar como "rainha das ciências para os habitantes da altera civitas na sua peregrinação através deste mundo temporário” (MILBANK, 2006, p. 382).

Outra linha teológica é do mundo oriental. Georges Florovsky e a 'síntese neopatrísitica' é um divisor de águas na teologia oriental. A proposta teológica de Florovsky é 'voltar aos pais da igreja'. Assim proposta, a patrística oferece uma norma para avaliar todas as tentativas teológicas posteriores. A preocupação imediata de Florovsky era tirar a igreja russa do cativeiro ocidental que distorceu a identidade teológica oriental. Nisto ele rebateu diretamente figuras contemporâneas tais como Sergius Bulgakov e Nicolas Berdayev, os relegando à categoria de "filósofo religioso" por seu uso de filosofias ocidentais na teologia. Ao mesmo tempo. Florovsky percebeu que a única maneira de superar as divisões cristãs internas era voltando à "mente comum da igreja primitiva" (GAVRILYUK, 2015, p. 1).

A "síntese neopatrística" é fundamental à compreensão das correntes teológicas ortodoxas (orientais) no século XX. Mas a mesma é difícil de definir com precisão. Andrew Louth observou que o termo tem afinidade com "neoKantianismo" e "neoThomismo" ocidentais. São todos movimentos que envolvem um resgate do passado e um engajamento com problemas modernos (LOUTH, 2008, p. 188). Por isso, nos seus momentos mais otimistas, Florovsky afirmava que a síntese neopatrística não era um exercício em história, ou apenas um apelo à antiguidade. Numa virada escatológica, a teologia da patrística vem do futuro para a Florovsky. Ela é novidade (FLOROVSKY, 1961).

Milbank e Florovsky são teólogos muito diferentes. Porém, eles compartilham uma suspeita da influência distorcida da filosofia na teologia (tanto ocidental quanto oriental). Nisto, eles são muito próximos ao Tertuliano: o 
que Atenas tem a ver com Jerusalém? Porém, a proposta dos dois teólogos não é suficiente para compreender Tertuliano como teólogo africano que utiliza uma hermenêutica africana. Milbank propõe uma volta ao cristianismo primitivo latino, principalmente na teologia agostiniana. Florovsky propõe uma volta ao cristianismo primitivo grego, principalmente nos pais gregos. Assim, a "ortodoxia radical" e a "síntese neopatrística" correm o risco de normatizar propostas já estabelecidas em leituras posteriores, mas baseadas nas fontes do cristianismo primitivo, em vez de engajar as próprias fontes para ouvir algo novo.

\section{Teologia em busca do seu método}

Milbank e Florovsky sinalizam a importância do cristianismo primitivo para a teologia. Eles não explicam como compreender este cristianismo primitivo, sem simplesmente reforçar leituras cativas, hegemônicas e normativas. Consideramos duas perspectivas importantes da teologia do século XX para aproximar Tertuliano e seu legado teológico. A primeira perspectiva é o passo metodológico da teologia da libertação que propõe teologia como "ato segundo". Nesta linha, aproxima-se o trabalho teológico de Juan Luis Segundo. A segunda perspectiva é a busca da teologia negra e teologia africana para uma hermenêutica negra/africana. Nesta linha, utilizam-se as propostas de James Cone e Kwame Bediako, notando a influência de Placide Tempels.

A perspectiva da libertação da teologia iniciada com Juan Luis Segundo, e aprofundada por Clodovis Boff, Marcella Althaus-Reid e Ivan Petrella, entre outros, fundamentalmente posiciona a teologia latino-americana em diálogo crítico com a herança latina e ocidental. O foco destes pensadores foi "a mediação sócio analítica" no fazer teologia (BOFF, 1982). O conceito da "mediação sócio analítica" permitia que a libertação da teologia passasse a propor uma reconfiguração da relação entre teologia e ciências sociais. Esta proposta é ligeiramente diferente da proposta de John Milbank e a "ortodoxia radical". Na proposta de Juan Luis Segundo, a teologia torna-se consciente e articula que ela é "ato segundo". Brinco: se a teologia não é mais considerada "rainha das ciências" pela teologia da libertação, pelo menos pela proposta da teologia da libertação ela passa ser "enfant terrible" das ciências sociais.

C. Boff, depois de muita reflexão, decidiu publicamente repudiar a teologia da libertação como "ato segundo" e voltou para o berço da teologia latina e ocidental (BOFF, 2007). Marcella Althaus-Reid libertou a teologia por meio das teorias queer (ALTHAUS-REID, 2004), e Ivan Petrella minava, de forma frutífera, a relação entre teologia de libertação e outras disciplinas acadêmicas 
contemporâneas (PETRELLA, 2006). O que a libertação da teologia pouco investigou foi à libertação da teologia clássica pela própria tradição da teologia com as ferramentas da teologia da libertação. O próprio J. L. Segundo comentou que a situação estava incerta quanto ao futuro da teologia da libertação em relação a teologia clássica (SEGUNDO, 1982, p. 4). A proposta aqui - a libertação da teologia clássica pela teologia da libertação - pode até soar estranho uma vez que a libertação da teologia propõe teologia como "ato segundo". Em termos simples, a interrogação à proposta, é como a teologia poderia libertar a teologia? Não é uma incoerência lógica e negação da "mediação sócio analítica" e da práxis de teologia da libertação como "ato segundo"?

A "mediação sócio analítica" se tornou peça fundamental para o diálogo da teologia da libertação com outros saberes e práticas. Com a exceção de Juan Luis Segundo, poucos(as) teólogos(as) da libertação empregaram "a mediação sócio analítica" em relação a própria tradição teológica. A proposta de J. L. Segundo quanto esta "mediação sócio analítico" ficou conhecida como o "círculo hermenêutico" conforme esboçado no seu livro A Libertação da Teologia, livro fruto de período de ensino em Harvard nos Estados Unidos (SEGUNDO, 1982). J. L. Segundo exemplifica como empregar "a mediação sócio analítica” à teologia num dos seus últimos livros, O Dogma que Liberta. De certo modo, J. L. Segundo manteve que a teologia é "ato segundo", mas neste "ato segundo" ele não desconsiderava que a herança teológica - a tradição teológica - poderia ser lida de forma crítica com a "mediação sócio analítica":

Meu 'que fazer' teológico... me fez evitar dois escolhos, os mais perigosos e tentadores:... ter que ensinar ou propor uma parte (ou tratado) de um sistema pré-estabelecido num programa, e por consequência, sem conexão provável com os interesses e perguntas dos ouvintes ou interlocutores; ou, por outro lado, ter que responder com receitas demasiado rápidas e sumárias a perguntas inspiradas numa versão simplista do método chamado de 'revisão de vida': ver-julgar-agir (2000, p. 25).

É nesta linha proposta por J. L. Segundo que queremos trilhar. Queremos trazer "a mediação sócio analítica" para o dentro da tradição teológica e, ao mesmo tempo, evitar "os dois escolhos perigosos e tentadores" identificados por J. L. Segundo: teologia pré-estabelecida e teologia de receita rápida. Em resumo, propomos libertar Tertuliano das perspectivas que o interpretam como teólogo latino, e, portanto pedra fundamental da tradição latina, ocidental, católico-romana e protestante; percursor de muitas ortodoxias cristãs (e heresias montanistas); e, problematizador da relação entre filosofia ocidental e teologia ocidental que hoje em dia se expressa por meio da divisão entre ciência e religião. 
A proposta de trabalhar com Tertuliano em termos da busca para uma hermenêutica africana ainda poderia parecer uma opção estranha. Já esboçamos objeções rápidas e sumárias acima. Mas, existem outras objeções, entre quais destacamos a teologia negra.

\section{A teologia negra e africana}

A proposta da teologia negra, associada com figuras tais como James Cone, Gayraud Wilmore e Jacqueline Grant revolucionou a teologia. Cone, Wilmore e Grant empregaram "a mediação sócio analítica" no contexto do movimento dos direitos civis nos EUA. A experiência e consciência negra, a igreja negra e a herança da escravidão foram todos propulsores da teologia negra.

Jacqueline Grant documentou esta "mediação sócio analítica" no seu livro, White Women's Christ and Black Women's Jesus. A teologia negra de Grant (Womanist theology) criticou a herança latina e ocidental da teologia, particularmente conforme vivida e articulada na Europa e os EUA. Mas, também, ela criticou outras teologias que empregaram 'a mediação sócio analítica' para criticar a herança latina e ocidental. Por exemplo, de forma sucinta, Grant disse, "Teologia feminista é inadequada por duas razões: ela é branca e ela é racista" (1989, p. 195).

Enquanto Grant identificou uma lacuna na "medição sócio analítica" de outras teologias críticas à herança latina e ocidental, James Cone identificou outra "vastidão completamente inexplorada" depois do desenvolvimento da teologia negra nos EUA: a África. Um jovem ganense o perguntou,

Mas por que vocês falam de Teologia Negra? Por que vocês não chamam a teologia que estamos fazendo hoje na África Teologia Africana? (1986, p. 356).

Cone refletiu:

Esta pergunta revela uma anomalia que indica uma vastidão completamente inexplorada de outras perguntas sobre situações políticas, sociais e intelectuais em ambos lados do Atlântico entre povos de descendência africana que, de uma maneira ou outra, receberam a mensagem sobre Jesus Cristo das mãos dos brancos (1986, p. 356).

Nas suas reflexões, James Cone começou elaborar a possibilidade de teologia africana com base na 'mediação sócio analítica' usada pela teologia negra. Ou seja, Cone propõe que a experiência e consciência negra (o movimento para direitos civis), a igreja negra e a herança da escravidão são, também, propulsores de uma teologia africana. Cone lembra a passagem 
bíblica de Salmo 68: 31: "Embaixadores reais virão do Egito; a Etiópia cedo estenderá para Deus as suas mãos" (1993). Ele aplica este recorte bíblico aos movimentos de nacionalismo africano e pan-africanismo. E, é nestes movimentos que ele identifica "os primeiros teólogos cristãos africanos ou negros ao sul do Saara e no novo mundo" (1986, p. 358). Ele cita nomes tais como Paul Cuffee, Daniel Choker, Dom Turner, Mangena Mokone, James M Dwane e John Chilembwe. Para Cone, estas pessoas são os primeiros teólogos cristãos africanos.

O movimento de direitos civis, o nacionalismo africano e o pan-africanismo pertencem à história. São fatores e momentos históricos que ainda influenciam a teologia. Não são peças de museu, como diria Marcella Althaus-Reid. Ela já havia advertido sobre o perigo de ensinar teologia da libertação como peça de museu. ${ }^{2}$ Os movimentos ainda influenciam a teologia negra e a teologia africana, e ainda existem como movimentos ativos e vivos. Mas o contexto mudou. Cone, por sua vez, não desconsiderava a possibilidade da teologia africana tornar uma teologia mais abrangente que a própria teologia negra e ele se animou com a possibilidade da chegada de um dia em que os dois lados do Atlântico fariam juntos uma teologia africana (1986, p. 371).

A teologia africana traça sua construção à patrística. Depois ela passa pelas categorias africanas de pensamento - metafísica e ontológica - esboçadas por Placide Tempels em sua obra Filosofia Bantu. A teologia da célebre obra, Perguntas sobre Padres Negros (1957) é uma forte tentativa de inserir a teologia africana no movimento de negritude que tem suas raízes no século XIX. Vincent Mulango se tornará uma referência importante para esta linha de teologia africana. A teologia de Mulango dialoga com o fundamento filosófico bantu de Tempels. Assim, ela abre um diálogo crítico com a herança latina e grega na teologia africana e busca alternativas "decoloniais" para a teologia africana. A obra filosófica de Placide Tempels oferece a Mulango e outros teólogos um aporte africano (bantu, no caso dele) para fazer teologia.

Queremos levar em consideração as observações da teologia africana e as observações de J. L. Segundo e examinar a figura e teologia de Tertuliano. É necessário fazer duas observações preliminares. A experiência e consciência negra, a igreja negra e a herança da escravidão (as "mediações sócio analíticas" da teologia negra) nos EUA são fundamentadas na proposição de Cone. Cone afirma que a mensagem sobre Jesus Cristo veio das mãos dos brancos. É possível aplicar esta mesma “mediação sócio analítica” à teologia africana,

2 Marcella Althaus-Reid falava de teologia como caminata. De acordo com Althaus-Reid, a caminata força a teologia da libertação a fazer teologia ao seu próprio modo e não ensinar sobre eventos históricos como concílios eclesiásticos e revoluções do século XX. 
particularmente nos movimentos de nacionalismo africano e pan-africanismo. Porém, tudo isso desconsidera a possibilidade que a mensagem sobre Jesus Cristo veio das mãos dos africanos. Isso é particularmente pertinente para a teologia africana, que Cone já enxergava como mais abrangente que a teologia negra. Ou seja, por viés de uma "mediação sócio analítica" na teologia é possível afirmar que a mensagem sobre Jesus Cristo veio das mãos dos africanos. A mensagem sobre Jesus Cristo que veio das mãos dos brancos é um "ato segundo", para empregar o conceito de J. L. Segundo.

É importante afirmar - contrário à leitura de James Cone - que a teologia está presente e sendo produzida na África por mais de 2000 anos. Ela não nasce no período das lutas decoloniais no século XX. Temos a presença de Simão, o cireneu no relato de Lucas sobre a crucificação de Jesus. Cirene é uma cidade no norte da África, atualmente na Líbia. Também, nos Atos dos Apóstolos, temos o relato do batismo do eunuco etíope por Felipe. Etiópia e Líbia, países africanos, aparecem nos relatos sobre a crucificação de Jesus e a emergente Igreja.

No cristianismo primitivo aparecem influentes teólogos e teólogas africanos. Tertuliano de Cartago (na Tunísia) e Agostinho de Hipona (atualmente a cidade de Annaba na Algéria), são exemplos desta teologia africana. Também, a influente 'escola de Alexandria' (no Egito) divulgou a teologia africana pelo continente e outras regiões do mundo cristão. Falamos aqui de teologia africana em termos geográficos.

John Baur (2001) notou que esta presença expressiva da teologia e cristianismo africanos se restringiu ao norte da Saara e o chifre da África nos primeiros séculos do cristianismo. Porém, Baur afirma que por seis séculos a África ofereceu liderança ao cristianismo (Egito na parte oriental ou mundo grego, e África do Norte na parte ocidental ou mundo latino). Apesar das observações de teólogos e teólogos atuais que interpretam a "teologia africana" como fruto de um processo político de descolonização (Cone entre outros), é importante lembrar que a teologia cristã está presente na África desde as páginas da Bíblia e o período do cristianismo primitivo.

\section{Tertuliano e a teologia africana}

Kwame Bediako descreve a teologia africana como, o momento na década 1960 quando a teologia na África se torna consciente que há uma tradição não-cristão de longos anos no continente. Como a teologia cristã dialoga com esta herança religiosa africana? (1992, p. 1). Assim, para Bediako (como para Cone, entre outros) a teologia africana é uma teologia que leva 
em consideração tanto esta herança religiosa não-cristã (ou pré-cristã) quanto as práticas culturais contemporâneas baseadas nesta herança religiosa.

Porém, Bediako faz um passo inovador para solucionar a questão "fé" (cristã) e "cultura" (africana) no seu livro perspicaz, Theology and Identity: the impact of culture upon Christian thought in the second century and modern Africa (1992). Ele revisita a patrística (o que ele chama de "Celso e seus amigos" (1992, p. 9) para descobrir a africanidade na patrística. O que motivou esta busca por parte de Bediako foram as críticas africanas anticristãs lideradas por Okot p'Bitek, que disseram que o problema fundamental da teologia africana é a introdução da metafísica grega ao pensamento religioso africano. Em particular, p'Bitek criticava a tentativa de reconciliar a herança missionária (branca) com a cultura africana que marcou as primeiras teologias africanas.

Bediako consegue mostrar que longe de aparecer no século XX, inspirada pelo teologia negra e teologia da libertação, a teologia africana já se posicionou na patrística pensando a fé cristã em categorias africanas. Para fazer isso, ele oferece uma discussão de textos de Taciano, Tertuliano, Justino e Clemente de Alexandria. A ligação entre os teólogos não é sua africanidade, mas a forma que a tradição teológica branca os julgou como heresias. Bediako abre uma discussão crítica sobre esta opinião teológica (branca), notando no caso de Tertuliano que leituras que tentam organizar o pensamento de Tertuliano em "ortodoxia" e "heresia" enfrentam o problema de cronologia nos escritos. Por exemplo, Adversus Praxean, que serve na classificação de Gerald Lewis Bary como texto do período "montanista", na verdade é um texto de suma importância para os concílios ecumênicos posteriores (BEDIAKO, 1992, p. 101). ${ }^{3}$ Também, Bediako afirma que abordagens de Tertuliano pela dicotomia "ortodoxia" e "heresia" perdem de vista que não há evidência que ele deixou a catolicidade da Igreja (1992, p. 101). "Montanismo" como categoria de heresia (como todas as categorias de heresia) apenas surge posteriormente. Neste caso, ele aparece na literatura cristã no século IV (200 anos posterior a teologia de Tertuliano).

"O que Atenas tem a ver com Jerusalém?" (STEVENSON, 2002, p. 167), frase célebre de Tertuliano em Prescrição contra Hereges percorre toda teologia latina e ocidental. A interpretação branca desta frase ocupa reflexões teológicas católico-romanas e protestantes até os dias de hoje. Nesta recepção branca, compreende-se que Tertuliano como "Pai Latino" desconfia que a filosofia grega seja uma fonte de heresia na teologia cristã. É uma posição contrária ao "Pai Grego" Clemente de Alexandria que vê na filosofia grega um caminho para Cristo em Stromata (STEVENSON, 2002, p. 184).

É neste texto que Tertuliano elabora seu conceito de Trindade tão importante a Igreja posterior. 
A mão branca da teologia interpreta Tertuliano e Clemente em termos de um sistema pré-estabelecido: mundo latino x mundo grego, Roma x Constantinopla, ocidente $\mathrm{x}$ oriente, católico-romano e protestante $\mathrm{x}$ ortodoxo. J. L. Segundo lembra que este tipo de sistema pré-estabelecido, e este programa teológico, é por consequência, sem conexão provável com os interesses e perguntas dos ouvintes ou interlocutores negros e africanos. James Cone lembra que a experiência e consciência negra e africana indica uma vastidão completamente inexplorada pela teologia branca pré-estabelecida. Kwame Bediako foi em busca desta herança africana na teologia cristã.

Deve-se lembrar de que Tertuliano e Clemente são africanos. Cartago e Alexandria são cidades africanas. Queremos sugerir que a teologia africana convida a teologia branca a ler a teologia de Tertuliano como sistema indígena africano do saber (African Indigenous Knowledge System). "O que Jerusalém tem a ver com Atenas" não é apenas uma questão percorrendo o sistema pré-estabelecido da teologia latina e ocidental branca, podemos lê-la com uma interrogação desde a experiência e consciência africana para articular um cristianismo como sistema indígena africano do saber.

Ela não é uma filosofia bantu nos termos esboçados por Tempels, mas a filosofia bantu não é o único sistema indígena africano do saber no continente africano. Em perspectiva, a mensagem sobre Jesus Cristo veio dos mãos dos brancos; nesse sentido, podemos ler Tertuliano, mas também Clemente e Agostinho entre tantos outros, como exponente da teologia africana e articulador de sistemas indígenas africanos do saber em diálogo e em contra partida com a filosofia grega e latina. Esta é a proposta perspicaz de Kwame Bediako.

\section{Tertuliano e a hermenêutica da teologia africana}

Justo L. González disse que:

Es interessante notar que los orígenes de la literatura cristiana em Latín no se hallan em Roma, sino em el Africa Septentrional... Durante vários siglos Africa fue no sólo el lugar de orígen, sino el centro del pensamento Cristiana em lengua latina. Em ella se forjó el vocabulário teológico que luego passaria a ser patrimônio de toda la Iglesia Occidental (1965, p. 197).

González aponta para uma possível compreensão do cristianismo africano como ponto estruturante da teologia, diferente do sistema pré-estabelecido latino. Ou seja, a teologia africana precede (e influencia) a teologia latina.

Deste modo, é importante aproximar os textos de Tertuliano como teologia africana e não apenas como teologia latina. Na sua introdução ao 
Tertuliano como teólogo africano Johannes Quasten já notou que Tertuliano escreveu em latim e grego:

Quatro das obras de Tertuliano, por exemplo, foram publicadas naquele idioma [grego], De spetaculis, De batismo, De virginibus velandis, De corona militis, e uma nunca apareceu em latim, De extasi (1986, p. 243).

Também, Quasten observou que enquanto Tertuliano é proeminente no cristianismo latino, é um exagero considera-lo "criador do latim eclesial" (1986, p. 249). Ou seja, na opinião de Quasten há evidência que Tertuliano é muito mais que apenas um teólogo latino (como a tradição teológica (branca) o rotulou.

A "mediação sócio analítica" da teologia da libertação permite que essa leitura africana se torna possível e que a libertação da teologia clássica seja possível pela própria tradição teológica. Tertuliano se posiciona como teólogo africano, articulador de uma teologia africana como sistema indígena africano do saber. Neste sentido a frase célebre de Tertuliano se posiciona nos seguintes termos: o que o mundo grego tem a ver com a África? (É a pergunta crítica de p'Betek à elaboração da teologia africana do século XX.) Ou, pode ser a pergunta, o que o mundo latino tem a ver com a África? (É a exploração da teologia africana liderada por Vincent Mulango, Bolajo Idowu, John Mbiti, Mulago gwa Cikala Musharhamina, Byang Kato e Kwame Bediako, entre outros.) O cristianismo africano poderia forjar um caminho sem Atenas, Roma e Jerusalém?

Duas dificuldades principais se levantam em tentar abordar Tertuliano desta forma "mais abrangente", para usar a frase de James Cone em se referir à teologia africana. Primeiro, Tertuliano é frequentemente interpretado como pedra fundamental da teologia latina e ocidental e também como percursor de muitas ortodoxias cristãs declaradas sensus fidelium pelos concílios ecumênicos. Segundo, ele não é teólogo negro (no sentido técnico de James Cone) e ele não estrutura sua teologia a partir da experiência da escravidão nem do recebimento da mensagem sobre Jesus Cristo das mãos dos brancos. Também, a teologia de Tertuliano não opera nas categorias filosóficas bantus.

Como notou Justo González, "Tertuliano es antes que nada um pensador prático e concreto" (1965, p. 200). E, é nesta linha que interpretamos sua teologia como "ato segundo" que tenta evitar dois escolhos perigosos e tentadores: teologia pré-estabelecida e teologia de receita rápida. Tertuliano é um pensador prático e concreto da África. ${ }^{4}$ Seu contexto é a igreja africana (ainda

4 Tertuliano foi formado no mundo greco-romano. Os país eram pagãos, ele advogou em Roma e só depois da sua conversão foi morar em Cartago (QUASTEN, 1986, p. 246). 
que seja uma igreja sob a influência de Roma e faz parte do mundo greco-romano). Este contexto sofre com a imposição greco-romana em termos de política, economia, cultura e práticas religiosas. Na igreja africana, Tertuliano enxerga uma fonte de práticas diferentes com bases diferentes - teologia e não filosofia, por exemplo - para o povo africano.

Como afirma Bediako, Tertuliano é essencialmente defensivo (apologético) na sua teologia (1992, p. 124). Assim, é fácil de ler Tertuliano por meio de "proposições informativas" ou "reivindicações de verdades sobre realidades objetivas" (para lembrar de George Lindbeck). A defesa da fé proposições informativas (verdades) - foi mais importante para Tertuliano que o fundamento da fé (BEDIAKO, 1992, p. 125). Por isso a rejeição de Atenas por Tertuliano.

Porém, Bediako introduz uma perspectiva sobre Tertuliano muito frutífera para compreender sua defesa da fé e para lê-lo como teólogo africano. "Uma pessoa se torna cristão; não se nasce cristão" (1992, p. 125); na leitura de Bediako, esta frase de Tertuliano de Apologeticum abre a possibilidade de cristianismo se tornar africano tanto na patrística de Tertuliano quanto na África contemporânea. É preciso afirmar a 'regra da fé' diante do mundo e das categorias gregas e latinas, não necessariamente por meio deles. Esta leitura de Bediako sobre Tertuliano é muito próxima (mas não igual) as propostas teológicas de Milbank e Florovsky em relação a teologia ocidental e oriental. Tertuliano e seu legado teológico faz parte de várias teologias contemporâneas demonstrando a influência duradora para a tradição teológica.

\section{Conclusão}

Apesar da escassez de textos de Tertuliano disponível em língua portuguesa, e ciente da divisão dos campos disciplinares na academia brasileira para ler, interpretar e discutir as obras de Tertuliano, este artigo procurou situar Tertuliano no campo da teologia e mostrar sua importância para várias teologias contemporâneas. A volta à patrística na teologia ocidental e oriente no século XX (a "ortodoxia radical" e a "síntese neopatrística") é um dos caminhos pelos quais é possível reavaliar a influência de Tertuliano. Porém, é necessário considerar contribuições da teologia da libertação e da teologia negra para descobrir um círculo hermenêutico que permite tirar Tertuliano dos pressupostos latinos, ocidentais e brancos da teologia.

Começamos com a pergunta, como ensinar Tertuliano na academia, e especificamente num curso de teologia? A resposta vem por meio do teólogo africano Kwame Bediako. É preciso situar Tertuliano como teólogo africano e 
dialoga com uma metafísica e ontologia não greco-romana. Assim, abre novas interpretações do saber prático e concreto da igreja africana do século II, antecipando que quase 1800 anos a importância da assimilação e convivência do cristianismo à cultura africana. Tertuliano oferece esta possibilidade para a teologia africana, e a teologia em geral.

\section{Referências bibliográficas}

ALTHAUS-REID, Marcella. From feminist theology to indecent theology. London: SCM Press, 2004.

ALVES, Rubem. Religião e repressão. São Paulo: Loyola, 2005.

BAUR, John, 2000 Ans de cristianisme en Afrique: une histoire de l'église africaine. Kinshasa: Paulines, 2001.

BEDIAKO, Kwame. Theology and identity: the impact of culture upon Christian thought in the second century and modern Africa. Oxford: Regnum Books, 1992.

BOFF, Clodovis. Teologia e prática: teologia do político e suas mediações. Petrópolis: Vozes, 1982.

BOFF, Clodovis. Teologia da Libertação e volta ao fundamento. Revista Eclesiástica Brasileira, v. 67, n. 268, p. 1001-1022, 2007.

BÍBLIA. Revista e Atualizada. Barueri: Sociedade Bíblica do Brasil, 1993.

FLOROVSKY, Georges. St Gregory Palamas and the Tradition of the Fathers. Sobornost, v. 4, n. 4, p. 165-176, 1961.

GONZÁLEZ, Justo L. Historia del pensamiento cristiano. Buenos Aires: Methopress, 1965.

GONZÁLEZ, Justo L. Dicionário ilustrado dos intérpretes da fé. Santo André: Academia Cristã, 2005.

GRANT, Jacqueline. White women's Christ and black women's Jesus. Atlanta: Scholars Press, 1989.

GAVRILYUK, Paul. L. Georges Florovsky and the Russian religious renaissance. Oxford: Oxford University Press, 2015.

GAYRAUD, Wilmore e CONE, James. Teologia Negra. São Paulo: Paulinas, 1986.

JEANROND, Werner. Theological hermeneutics: development and significance. London: SCM Press, 1994.

LINDBECK, George. The nature of doctrine: religion and theology in a postliberal age. London: Westminster John Knox, 1984.

LOUTH, Andrew. The Patristic revival and its protagonists. In: CUNNINGHAM, Mary. B; THEOKRITOFF, Elizabeth (orgs). Orthodox christian theology. London: Blackwell, 2008, p. 188-202.

MARSDEN, George. Understanding fundamentalism and evangelicalism. Michigan: Eerdmans, 1991.

MILBANK, John. Theology and social theory: beyond secular reason. London: Blackwell, 2006. 
PETRELLA, Ivan. The future of Liberation Theology: an argument and manifesto. London: SCM Press, 2006.

QUASTEN, Johannes. Patrology. Vol. II. Maryland: Christian Classics, 1986.

SEGUNDO, Juan Luis. The Liberation of Theology. Maryknoll: Orbis, 1982

SEGUNDO, Juan Luis. O Dogma que liberta: fé, revelação e magistério dogmático. São Paulo: Paulinas, 2000.

STEVENSON, J. A new Eusebius: documents illustrating the history of the Church to AD337. London: SPCK, 2002.

WOLTERSTORFF, Nicholas. Tertullian's Enduring Question. In: Special Issue Lilly Fellows Program in the Humanities and Arts. Notre Dame, IN: University of Notre Dame, 1999, p. 6-17.

Submetido em: 28-2-2020

Aceito em: 18-4-2020 